\title{
Clinical Predictors of Poorly-Controlled Childhood Epilepsy: A Case-Control Study
}

\author{
Mohammad Asaduzzaman *1, Md Mizanur Rahman ${ }^{2}$, Mohammad Nadim Hasan ${ }^{3}$
}

\section{Abstract}

Introduction:The aim of the present study was to determine clinical factors associated with poorly controlled epilepsy. Materials and Methods: This retrospective study was performed from January 2007 to December 2008 at Paediatric Neurology outpatient department in Bangabandhu Sheikh Mujib Medical University, Dhaka, among the children with epilepsy of 7 months to 15 years age who had history of at least 6 months treatment with rational antiepileptic drugs daily with adequate compliance. There were two groups of patients; group 1, consisted of 50 poorly controlled epilepsy patients and group 2, comprised 50 well-controlled epilepsy patients. We retrospectively reviewed EEGs and medical records from these children. Features of clinical findings were compared between the two groups. Results: In this study, age of onset of initial seizure before 1 year, mixed type of seizure, infantile spasm, high initial seizure frequency (daily seizure), symptomatic etiology, mental retardation, neonatal seizure and more than 20 seizures before starting treatment were also found to be significant clinical predictors of poorly controlled epilepsy. Multivariate analysis detected 2 independent clinical predictors of poorly controlled epilepsy: mixed seizures and more than 20 seizures before starting treatment. Conclusions: The study showed several clinical factors that can be identified early in the course of childhood epilepsy which can predict development of poor seizure control. Knowledge of these factors will help us to discriminate our patients and pay more attention to those at risk of developing poorly controlled epilepsy.

Keywords: Clinical factors, Poorly controlled epilepsy

Number of Tables: 06; Number of References: 23; Number of Correspondence: 03.

*1. Corresponding Author:

\section{Dr. Mohammad Asaduzzaman}

MD (Paediatrics), Assistant Professor

Department of Paediatrics

Sheikh Hasina Medical College, Jamalpur.

Email: drmdzaman1973@gmail.com

Mobile Number: 01712000511

2. Professor Md. Mizanur Rahman

Professor and Chairman

Department of Paediatric Neurology

Bangabandhu Sheikh Mujib Medical University Dhaka.

3. Dr. Mohammad Nadim Hasan

FCPS (Medicine), Assistant Professor

Department of Medicine

Sheikh Hasina Medical College, Jamalpur.

\section{Introduction}

Seizures affect $4-7 \%$ of children ${ }^{1}$. The prevalence of epilepsy is 4-8/1000 population. This is western data, but the prevalence may be higher in developing countries due to high incidence of CNS infection, birth asphyxia and consanguinity related metabolic diseases ${ }^{1}$. The largest number of newly diagnosed patients with epilepsy occurs between birth and 2 years of age ${ }^{2}$. Epilepsy is considered to be present when two or more unprovoked seizures occur at an interval greater than 24 hours apart ${ }^{3}$.
One or more seizures per month over a period of 6 months or more even after experiencing trials of at least two different antiepileptic drugs alone or in combination at optimum doses with adequate compliance is called intractable epilepsy ${ }^{4}$. Epilepsy is refractory when seizures are so frequent or severe that they limit the patient's ability to live life fully according to his or her wishes or necessitate the use of medications that, although effective, produce adverse effects ${ }^{5}$.

Fortunately, most children with epilepsy do well when treated with an antiepileptic drug 6 . Numerous studies have reported predictors of favorable outcome of epileptic seizures in children and adults. Most report that $70-80 \%$ of patients eventually become seizure free ${ }^{7}$. But $10-20 \%$ of children with epilepsy have persistent seizures refractory to drugs, and those cases pose a diagnostic and management challenge ${ }^{3}$. However, what becomes of the group of children who continue to have seizures despite adequate trials of drugs? Although this is a small group of children, the medical, social, and economic consequences of poorly controlled seizures can be enormous. These children are at high risk for behavioral and academic difficulties ${ }^{8}$. In addition to the often catastrophic effects of uncontrolled seizures on the child, the burden on the parents of dealing with the multitude of daily problems accompanying intractable epilepsy cannot be underestimated ${ }^{2}$.

The best predictors of seizure remission include an early response to therapy, a low frequency of seizures and normal mental development ${ }^{9}$. On the other hand Camfield et al. ${ }^{10}$ reported that an absence of neonatal seizure, older age at onset, normal intelligence and less than 20 seizures before initiation of treatment were all significant predictors of good outcome. Strong association was noted between intractable epilepsy and several factors: infantile spasm, remote symptomatic epilepsy, a history of status epilepticus before the diagnosis of epilepsy, neonatal seizure, and microcephaly ${ }^{11}$. There are a number of 
other clinical factors which are predictors of poor prognosis. A prospective case-control study showed that onset of seizure before 1 year of age, developmental delay, and abnormal brain imaging- were important predictors of intractable childhood epilepsy ${ }^{12}$. Very little is known about the childhood epilepsies in Bangladesh ${ }^{13}$. As mentioned by Banu et $a{ }^{13}$ factors most predictive of poor seizure remission were: multiple types of seizures, poor cognition at presentation, high rates of seizures, associated motor disability and EEG abnormalities.

As literatures were reviewed there were no published data about this type of study in our country. This study is intended to provide clinical information regarding poorly controlled epilepsy that may guide the physician for early identification of these patients for counseling their families, selecting patients for intensive investigations and treatment, as well as early consideration of epilepsy surgery to prevent consequences of poorly controlled epilepsy on quality of life.

\section{Materials and Methods}

This case-control study was conducted from January 2007 to December 2008 at Paediatric Neurology OPD, Bangabandhu Sheikh Mujib Medical University. 50 cases of intractable epilepsy in group-1 and 50 cases of well-controlled epilepsy in group-2 were enrolled in the study. Children of either sex with epilepsy, aged 7 months to 15 years with history of at least one unprovoked seizure per month for 6 or more months and history of treatment with 2 or more rational antiepileptic drugs (AED) daily, either singly or in combination for at least 6 months and adequate compliance to antiepileptic drugs were considered as case. Children of either sex with epilepsy, aged 7 months to 15 years who had been seizure-free during 6 months after start of treatment were considered as control. Poorly controlled epilepsy was defined as one or more seizure per month over a period of 6 months or more even after experiencing trials of at least two different antiepileptic drugs alone or in combination at optimum doses with adequate compliance. Well-controlled epilepsy was defined as no seizure during 6 months after start of treatment with AED.

Once the child was reporting, a structured questionnaire was completed, containing pre-defined variables of clinical information that may help predicting the poor seizure control. Then a detailed history including gender, age of onset, number of seizures before starting the treatment, type of epilepsy, character of seizure, status epilepticus, initial seizure frequency, history of neonatal seizures, family history of epilepsy, history of complex febrile seizure, treatment history, etc. were recorded and medical records were reviewed. Details regarding antiepileptic drugs were recorded i.e. number of drugs, duration of therapy, dosage and compliance. It was noted whether the choice of drugs were correct or incorrect in relation to seizure type and the dosage schedule was proper according to body weight. Thorough physical examination including neurodevelopmental and psychological assessment was done. All study patients were seen by a consultant Paediatric Neurologist of the unit. Seizures were classified using the International League Against Epilepsy (ILAE) classification of epileptic seizure. First Interictal EEG recordings obtained with a 19 channel Electroencephalograph, employing scalp electrodes placed according to the international 10-20 system were studied. Serum drug level was not measured. An antiepileptic drug was considered to have failed if it did not control seizures in spite of good compliance or if medication was discontinued because of unacceptable side effects. A drug used acutely to treat status epilepticus was not counted as one of the two AEDs. Child was a case or a control. Group1 consisted of poorly controlled epilepsy patients and Group2 comprised well-controlled epilepsy patients. A comparison of various clinical factors between the two groups was done. Data were analyzed using statistical package SPSS (version 15.0). Standard tests of significance, such as Chi-square test was applied for categorical variables and ' $\mathrm{t}$ ' test was done for quantitative variables. The Odds ratio (OR) was used as estimation of risk to indicate the magnitude of association between each factor and poorly-controlled epilepsy. 95\% confidence interval (CI) and $\mathrm{p}$ values were also computed. P-value of $<0.05$ was considered significant. Multivariate analysis was performed to choose independently significant factors among the many significant factors in bivariate analysis.

\section{Results}

Table I shows that $54 \%$ of the poorly-controlled epilepsy patients and $44 \%$ of well controlled epilepsy patients were between 1-5 years age group. However there was wide spread distribution in different age groups. The mean age was found to be $4.59 \pm 3.19$ years in poorly-controlled group and $5.91 \pm 3.72$ years in well- controlled group. No significant statistical difference was observed between poorly-controlled and well-controlled group in respect to age $(p=0.062)$. In poorly-controlled group $60.0 \%$ were males and $40.0 \%$ were females, while in well-controlled group males and females were $66.0 \%$ and $34.0 \%$ respectively. There was no significant statistical difference between the two groups in respect to $\operatorname{sex}(\mathrm{p}=0.534)$.

Table-I: Distribution of the subjects by demographic variables $(n=100)$.

\begin{tabular}{|c|c|c|c|c|}
\hline \multirow{3}{*}{\multicolumn{2}{|c|}{ Variables }} & \multicolumn{2}{|l|}{ Groups } & \multirow[t]{3}{*}{ p value } \\
\hline & & \multirow{2}{*}{$\begin{array}{l}\text { Group1 }(\mathrm{n}=50) \\
\text { No }(\%)\end{array}$} & Group $2(n=50)$ & \\
\hline & & & No $(\%)$ & \\
\hline \multicolumn{5}{|c|}{ Age (year) } \\
\hline o & $\leq 1$ year & $5(10.0)$ & $1(2.0)$ & \\
\hline $\mathrm{o}$ & $1-5$ years & $27(54.0)$ & $22(44.0)$ & \\
\hline $\mathrm{o}$ & $5-10$ years & $16(32.0)$ & $20(40.0)$ & \\
\hline o & $>10$ years & $2(4.0)$ & $7(14.0)$ & \\
\hline \multicolumn{2}{|c|}{ Mean \pm SD } & $4.59 \pm 3.19$ & $5.91 \pm 3.72$ & $0.062^{\mathrm{NS}(\mathrm{a})}$ \\
\hline \multicolumn{5}{|c|}{ Sex } \\
\hline o & Female & $20(40.0)$ & $17(34.0)$ & $.534^{\mathrm{NS}(\mathrm{b})}$ \\
\hline o & Male & $30(60.0)$ & $33(66.0)$ & \\
\hline
\end{tabular}


${ }^{a}$ Unpaired $t$ test was done to measure the level of significance. bChi-square test was done to measure the level of significance. $\mathrm{NS}=$ not significant.

Table: II demonstrates that as initial seizure type according to site of onset, generalized seizure was significantly higher in poorly-controlled group than in well-controlled group $(62.0 \%$ vs. $40.0 \%$; $=0.028)$. On the other hand in wellcontrolled group focal onset was significantly higher than in poorly controlled group $(36.0 \%$ vs. $18 \%$; $=0.043)$. Focal with secondary generalization showed no significant difference between the two groups ( $p>0.05)$.

Table II: Distribution of the subjects by initial seizure type according to site of onset $(n=100)$.

\begin{tabular}{llccr}
\hline & \multicolumn{3}{c}{ Groups } & \\
\cline { 3 - 4 } Initial seizure type & $\begin{array}{c}\text { Group1 (n=50) } \\
\text { No (\%) }\end{array}$ & $\begin{array}{c}\text { Group 2 (n=50) } \\
\text { No (\%) }\end{array}$ & \\
\hline o & Focal onset & $9(18.0)$ & $18(36.0)$ & $0.043^{*}$ \\
o & Generalized onset & $31(62.0)$ & $20(40.0)$ & $0.028^{*}$ \\
o & $\begin{array}{l}\text { Focal with secondary } 10(20.0) \\
\text { generalization }\end{array}$ & $12(24.0)$ & $0.629^{\text {NS }}$ \\
\hline
\end{tabular}

Chi-square test was done to measure the level of significance. $* \mathrm{p}<0.05 \mathrm{n}=$ number of patients $\mathrm{NS}=$ not significant.

Table III shows that in poorly-controlled group mixed seizure was significantly higher than in well-controlled group $(30.0 \%$ vs. $4.0 \%$; $<0.001)$ and infantile spasm was also found to be significantly higher in poorly-controlled group compared to well-controlled group $(16.0 \%$ vs. $4.0 \%$; $\mathrm{p}<0.05)$. In well-controlled group tonic-clonic seizure was significantly higher than in poorly-controlled group $(48.0 \%$ vs. $16.0 \%$; $<<0.001)$.

Table III: Distribution of the subjects by initial seizure character $(n=100)$.

\begin{tabular}{llll}
\hline \multirow{2}{*}{$\begin{array}{l}\text { Initial } \\
\text { seizure } \\
\text { character }\end{array}$} & $\begin{array}{c}\text { Group1(n=50) } \\
\text { No (\%) }\end{array}$ & \multicolumn{1}{c}{$\begin{array}{c}\text { Group 2(n=50) } \\
\text { No (\%) }\end{array}$} \\
\cline { 2 - 4 } & $8(16.0)$ & $13(26.0)$ & $0.220^{\mathrm{NS}}$ \\
Tonic & $5(10.0)$ & $5(10.0)$ & $0.999^{\mathrm{NS}}$ \\
Clonic & $8(16.0)$ & $24(48.0)$ & $<0.001^{* *}$ \\
Tonic-clonic & $6(12.0)$ & $4(8.0)$ & $0.505^{\mathrm{NS}}$ \\
Myoclonic & $8(16.0)$ & $2(4.0)$ & $0.046^{*}$ \\
Infantile spasm & $<0.001^{* *}$ \\
Mixed & $15(30.0)$ & $2(4.0)$ & $<0$ \\
Total & $50(100.0)$ & $50(100.0)$ \\
\hline
\end{tabular}

Chi-square test was done to measure the level of significance. $* \mathrm{p}<0.05$. $* \mathrm{p}<0.001$, NS $=$ not significant.

Table IV demonstrates that daily onset of seizure was significantly higher in poorly controlled group and was found to be $78.0 \%$ in contrast to $32.0 \%$ in well controlled group $(\mathrm{p}<0.001)$. On the other hand, seizure frequency of $<1 /$ month was significantly higher in well-controlled group compared to poorly-controlled group (52\% vs.4.0\%; p<0.001).
Table-IV: Distribution of the subjects by initial seizure frequency $(n=100)$

\begin{tabular}{llll}
\hline & \multicolumn{2}{c}{ Groups } & \\
\cline { 2 - 3 } $\begin{array}{l}\text { Initial seizure } \\
\text { frequency }\end{array}$ & $\begin{array}{l}\text { Group1(n=50) } \\
\text { No (\%) }\end{array}$ & $\begin{array}{l}\text { Group2(n=50) } \\
\text { No (\%) }\end{array}$ & p value \\
\hline$<1 /$ month & $2(4.0)$ & $26(52.0)$ & $<0.001^{* * *}$ \\
1-4/months & $6(12.0)$ & $5(10.0)$ & $0.749^{\text {NS }}$ \\
1-6/week3 & $(6.0)$ & $3(6.0)$ & $0.999^{\text {NS }}$ \\
Daily & $39(78.0)$ & $16(32.0)$ & $<0.001^{* *}$ \\
Total & $50(100.0)$ & $50(100.0)$ & \\
\hline
\end{tabular}

Chi-square test was done to measure the level of significance. ${ }^{* *} \mathrm{p}<0.001$. NS $=$ not significant

Table $\mathrm{V}$ demonstrates that if age of onset of initial seizure was $\leq 1$ year $72.0 \%$ patients developed poorly-controlled epilepsy compared to only $42.0 \%$ if onset was $>1$ year $(\mathrm{p}=0.002)$.

Mental retardation, neonatal seizure and more than 20 seizures before starting treatment were significantly higher among poorly-controlled group than those in well-controlled group $(70.0 \%$ vs. $32.0 \%, \mathrm{p}<0.001 ; 38.0 \%$ vs. $10.0 \%, \mathrm{p}<0.001 ; 82.0 \%$ vs. $28.0 \%, \mathrm{p}<0.001$ respectively). Symptomatic etiology was significantly higher in poorly-controlled group and was present in $74 \%$ patients compared to $42 \%$ of patients in well-controlled group $(\mathrm{p}<0.001)$, whereas in well-controlled group idiopathic epilepsy was significantly higher than in poorly-controlled group (54\% vs. $18.0 \%$; $<<0.001)$.

Table-V: Distribution of the subjects by other clinical predictors of poorly-controlled epilepsy $(n=100)$.

\begin{tabular}{|c|c|c|c|}
\hline \multirow[b]{2}{*}{ Variables } & \multicolumn{2}{|l|}{ Groups } & \multirow[b]{2}{*}{$p$ value } \\
\hline & $\begin{array}{l}\mathrm{p} 1(\mathrm{n}=50) \\
(\%)\end{array}$ & $\begin{array}{c}\text { Group2(n=50) } \\
\text { No }(\%)\end{array}$ & \\
\hline $\begin{array}{l}\text { Age of onset of initial } \\
\text { seizure ( } \leq 1 \text { year) }\end{array}$ & $36(72.0)$ & $21(42.0)$ & $0.002 *$ \\
\hline $\begin{array}{l}\text { Status epilepticus } \\
\text { before } 1 \text { st visit }\end{array}$ & $11(22.0)$ & $5(10.0)$ & $0.102^{\mathrm{NS}}$ \\
\hline $\begin{array}{l}\text { Complex febrile } \\
\text { seizure before } 1 \text { st } \\
\text { unprovoked seizure }\end{array}$ & $4(8.0)$ & $9(18.0)$ & $0.137^{\mathrm{NS}}$ \\
\hline $\begin{array}{l}\text { Family history of } \\
\text { seizure }\end{array}$ & $4(8.0)$ & $4(8.0)$ & $0.999^{\mathrm{NS}}$ \\
\hline $\begin{array}{l}\text { More than } 20 \text { seizures } \\
\text { before starting } \\
\text { treatment }\end{array}$ & $41(82.0)$ & $14(28.0)$ & $<0.001 * *$ \\
\hline Neonatal seizure & $19(38.0)$ & $5(10.0)$ & $<0.001 * *$ \\
\hline Mental retardation & $35(70.0)$ & $16(32.0)$ & $<0.001 * *$ \\
\hline $\begin{array}{c}\text { Etiology } \\
\bullet \quad \text { Symptomatic } \\
\bullet \quad \text { Idiopathic }\end{array}$ & $\begin{array}{l}37(74.0) \\
9(18.0)\end{array}$ & $\begin{array}{l}21(42.0) \\
27(54.0)\end{array}$ & $\begin{array}{l}<0.001 * * \\
<0.001 * *\end{array}$ \\
\hline
\end{tabular}

Chi-square test was done to measure the level of significance ${ }^{*} \mathrm{p}<0.05 * * \mathrm{p}<0.001 \mathrm{NS}=$ not significant 
Table VI demonstrates logistic regression analysis for predictors of poorly-controlled epilepsy. Nine independent variables were correlated with the dependent variable. In the final step of the regression analysis, two variables remained as most significant predictors of intractability. These were mixed seizures $(\mathrm{OR}=45.982)$ and more than 20 seizures before starting treatment $(\mathrm{OR}=5.269)$.

Table-VI: Logistic regression analysis for clinical predictors of poorly-controlled epilepsy.

\begin{tabular}{|c|c|c|c|c|}
\hline \multirow[b]{2}{*}{ Predictors } & \multicolumn{2}{|c|}{ Bivariate analysis } & \multicolumn{2}{|c|}{ Multivariate analysis } \\
\hline & $\begin{array}{l}\text { Poorly- } \\
\text { controlled } \\
\text { Group } \\
\text { No (\%) }\end{array}$ & $\begin{array}{l}\text { Well- } \\
\text { controlled } \\
\text { Group } \\
\text { No (\%) }\end{array}$ & $\mathrm{p}$ value & $\begin{array}{l}\text { Odds Ratio } \\
\text { (95\% CI) }\end{array}$ \\
\hline $\begin{array}{l}\text { Age of onset } \\
\text { of initial seizure }\end{array}$ & $\begin{array}{l}36(72.0) \\
(\leq 1 \text { year })\end{array}$ & $21(42.0)$ & 0.002 & $0.40(0.09-1.79)$ \\
\hline $\begin{array}{l}\text { Initial seizure } \\
\text { type (Generalized }\end{array}$ & $\begin{array}{l}31(62.0) \\
\text { onset) }\end{array}$ & $20(40.0)$ & 0.028 & $0.31(0.08-1.28)$ \\
\hline Infantile spasm & $8(16.0)$ & $2(4.0)$ & 0.046 & $5.914(0.76-46.32)$ \\
\hline Mixed seizures & s $15(30.0)$ & $2(4.0)$ & $<0.001$ & $45.982 *(4.54-465.68)$ \\
\hline $\begin{array}{l}\text { Initial seizure } \\
\text { frequency (daily }\end{array}$ & $\begin{array}{l}39(78.0) \\
\text { seizures })\end{array}$ & $16(32.0)$ & $<0.001$ & $3.448(0.78-15.25)$ \\
\hline $\begin{array}{l}\text { Symptomatic } \\
\text { epilepsy }\end{array}$ & $37(74.0)$ & $21(42.0)$ & $<0.001$ & $1.238(0.24-6.27)$ \\
\hline $\begin{array}{l}\text { Mental } \\
\text { retardation }\end{array}$ & $35(70.0)$ & $16(32.0)$ & $<0.001$ & $3.199(0.68-15.01)$ \\
\hline $\begin{array}{l}\text { Neonatal } \\
\text { seizure }\end{array}$ & $19(38.0)$ & $5(10.0)$ & $<0.001$ & $2.433(0.57-10.47)$ \\
\hline $\begin{array}{l}\text { More than } \\
20 \text { seizures }\end{array}$ & $41(82.0)$ & $14(28.0)$ & $<0.001$ & $5.269 *(1.03-27.04)$ \\
\hline
\end{tabular}

\section{Discussion}

This study was done to search the clinical factors that are associated with the poor control of childhood epilepsy. This retrospective study demonstrated that there were a number of clinical factors that were associated with poor seizure control. Early identification of these factors might help in planning early intervention.

Table I illustrates the demographic characteristics of the patients. Age (mean \pm SD) at presentation of poorly controlled group was $4.59 \pm 3.19$ years and that of well-controlled group was $5.91 \pm 3.72$ years. No significant statistical difference was observed between poorly controlled and well-controlled group in respect to age $(p=0.534)$. In poorly controlled group males were $(60.0 \%)$ and females were $(40.0 \%)$ and in well-controlled group males and females were $66.0 \%$ and $34.0 \%$ respectively. In both groups males were predominant. No significant statistical difference was observed in this study in respect to sex between poorly controlled and well-controlled group $(p=0.062)$ that is poor seizure control occurs with equal frequency in both sexes. This finding was supported by the study done by Kwan P et al. ${ }^{14}$ who did not find any significant difference in sex between the groups that become seizure free and the group with uncontrolled seizure. They found that $52 \%$ of the patients with uncontrolled epilepsy were male and $47 \%$ were female, whereas $47 \%$ male and $53 \%$ female were found in patients who were seizure free. But Malik et al. ${ }^{15}$ ound that male gender was a risk factor for intractable seizures $(p=0.001)$ and this finding was similar to that previously done by Akhondian et al. ${ }^{16}$ The male predominance in this study was more likely to be because of a selection bias.

Table II demonstrates that generalized seizures were found in the majority of poorly controlled epilepsy patients $(62 \%)$ followed by focal with secondary generalization $(20 \%)$ and focal $(18 \%)$. Similar finding was observed by Banu et al. ${ }^{13}$ They found generalized epilepsy in the majority of the children $(63.6 \%)$ followed by partial $(25.2 \%)$ epilepsy.

Table III shows that mixed seizure and infantile spasm was significantly associated with poor seizure control in this study. We found that in poorly controlled group mixed seizure was significantly higher than in well-controlled group (30.0\% vs. $4.0 \%$; $=0.001)$. Singvi et $\mathrm{al}^{17}$ also found mixed type of seizure as an adverse prognostic factor for the development of intractability. They found 14 out of 26 patients in the generalized group of intractable epilepsy to have more than 1 type of generalized seizures. Similar finding was described by Oskoui et al. ${ }^{18}$ who showed that multiple seizures type was a predictive factor of intractability $(\mathrm{OR}=6.5)$. Banu et al. ${ }^{13}$ found that multiple seizure type was an independent predictor of poor seizure remission $(\mathrm{OR}=4.42 ; \mathrm{p}=0.0001)$. Our study also found that infantile spasm was present in $16.0 \%$ of the patients in poorly controlled group compared to only $4.0 \%$ in well-controlled group $(\mathrm{p}=0.046)$. Berg et al. ${ }^{11}$ found infantile spasm in $19.7 \%$ cases of intractable epilepsy compared to $1 \%$ case in well-controlled group $(p=0.003)$. Kwong et al. ${ }^{19}$ also found that mixed seizures and infantile spasms were strongly associated with intractable epilepsy.

Initial high frequency of seizure (daily seizures) was found as a significant predictor of poor seizure control (Table IV). Similar results were found in other studies (Akhondian et al. ${ }^{16}$; Ko and Holmes ${ }^{20}$ and Chawla et al. ${ }^{4}$ ). Sillanpaa ${ }^{21}$ found $87.2 \%$ of patient having refractory epilepsy had high initial seizure frequency. Chawla et $\mathrm{al}^{4}$ found that $76 \%$ of intractable group compared to $22 \%$ of well-controlled epilepsy had daily seizure $(\mathrm{P}<0.001)$. Akhondian et $\mathrm{al}^{16}$ showed that, $66.7 \%$ of the patients in intractable group had daily seizures compared to $22.5 \%$ in well-controlled group $(\mathrm{p}<0.001)$. Ko and Holmes ${ }^{20}$ found daily seizures in $50.7 \%$ cases of intractable epilepsy compared to $25.6 \%$ of well- controlled epilepsy $(\mathrm{P}<0.001)$. Malignant syndromes of epilepsy which are difficult to control present with high frequency of seizure. But frequent seizure itself further deteriorates the developing brain which already has got pathology of seizure (Aicardi ${ }^{22}$ ).

Symptomatic etiology of seizure is an important predictor of poor seizure control (Table V). This study shows that $74 \%$ of cases in poorly controlled group had symptomatic etiology compared to $42 \%$ in well-controlled epilepsy 
$(p=0.001)$. Chawla et al. ${ }^{4}$ found that $80 \%$ of intractable group compared to $28 \%$ of well-controlled group had symptomatic etiology $(p<0.001)$. Berg et al. ${ }^{11}$ found only $33.3 \%$ of symptomatic epilepsy in control group compared to $68.4 \%$ in intractable group $(\mathrm{p}<0.001)$. Ko and Holmes ${ }^{20}$ found symptomatic etiology in $55.6 \%$ cases of intractable epilepsy compared to $20.5 \%$ of well- controlled epilepsy cases $(p<0.001)$. But in the present study the causes of the symptomatic etiology were not explored.

If age of onset of initial seizure was $\leq 1$ year $72.0 \%$ patients developed poorly controlled epilepsy compared to only $42.0 \%$ if onset was $>1$ year $(p=0.002)$ (Table V). Chawla et al. ${ }^{4}$ found $66 \%$ of patients in intractable group compared to $4 \%$ in well-controlled group had early onset of seizures $(\mathrm{p}=0.001)$. Berg et al. ${ }^{11}$ found $52.6 \%$ of intractable epilepsy cases compared to $9.4 \%$ of well-controlled epilepsy patient had early onset of seizures. Oktsuka et al. ${ }^{23}$ found that $53 \%$ of patients of early onset epilepsy had unfavourable outcome. Ko and Holmes also found it as an independent predictor of intractable epilepsy.

History of status epilepticus was not found as a predictor of poor seizure control $(p=0.102)$ (TableV). This finding was in contrast with the finding of Sillanpaa21and Berg et al. ${ }^{11}$, Ko and Holmes ${ }^{20}$ and Ohtsuka et al..$^{23}$. But most of the other studies had not found it as a predictor (Chawla et al. ${ }^{4}$; Malik et $\mathrm{al}^{15}$ ). It has been seen that subsequent episodes of status epilepticus occurred at various times during the seizure disorder, generally after a pattern of intractability has been established $^{22}$.

Family history of epilepsy had no significant association with poorly controlled epilepsy $(\mathrm{P}=0.999)$ (Table V). Other studies also showed similar results (Chawla et al. ${ }^{4}$; Banu et al. ${ }^{13}$, Malik et al. ${ }^{15}$, Ko and Holmes ${ }^{20}$, Akhondian et al. ${ }^{16}$ ).

Complex febrile seizure before first unprovoked seizure was not found to be a predictor of poor seizure control (Table V). Other studies showed similar results (Ko and Holmes ${ }^{20}$; Berg et al. ${ }^{11}$; Chawla et al. ${ }^{4}$ ). Incidence of febrile seizure in general population is 3-4 \% (Johnston3). Epileptic children suffer from febrile convulsion relatively more. Some claimed that this might be due to their low seizure threshold (Berg et al. ${ }^{11}$ ). This study also shows that $38.0 \%$ cases in poorly controlled group had history of neonatal seizure and it was a predictor of poor seizure control $(p=0.001)$. Berg et al. ${ }^{11}$ in their study showed that $17.1 \%$ of intractable patients compared to only $5.2 \%$ of well-controlled patients had neonatal seizure $(\mathrm{p}<0.01)$. Chawla et al.4 found $30 \%$ of intractable patients compared to only $2 \%$ of well-controlled epileptic patients had neonatal seizure $(p<0.001)$. Akhondian et al. ${ }^{16}$ showed $17.6 \%$ cases of neonatal seizure in intractable group and $5.0 \%$ in well-controlled group $(\mathrm{p}=0.018)$. When the developmental abnormality of the brain is severe they present early and one of the presentations may be neonatal seizure.

Patients who had a history of more than 20 seizures before initiation of treatment were found to be $82.0 \%$ in poorly controlled group (Table V). It was a significant predictor of poor seizure remission $(\mathrm{p}<0.001)$. Malik et al. ${ }^{15}$ found that $34 \%$ of patients in intractable group as compared to $12 \%$ in control group had history of $>10$ seizures before starting treatment $(p<0.001)$. Akhondian et al. ${ }^{16}$ found that patients who suffered from 20 generalized seizures before starting treatment are at risk for development of intractable epilepsy. Camfield et $\mathrm{al}^{10}$ showed that the fewer than ${ }^{21}$ seizures before initiation of treatment was a good predictor for seizure remission. Whereas Sillanpaa ${ }^{21}$ demonstrated that the number of seizures recorded before onset of drug therapy was not related to the probability of remission.

Mental retardation was found as a predictor of poor seizure remission $(p=0.001)$ as shown in table $V$. This finding was relevant to that done by Ko and Holmes ${ }^{20}$. They showed that $20.1 \%$ patients in intractable group compared to $2.6 \%$ in controlled group had mental retardation $(p=0.03)$. Singhi et al. ${ }^{17}$ found that mental retardation was present in $11.0 \%$ of intractable epilepsy patients and it was found to be a poor prognostic factor. Oskoui et al. ${ }^{18}$ showed that mental retardation at onset was a significant risk for intractability $(\mathrm{OR}=7.2)$.

Independent clinical predictors of poorly controlled epilepsy after multiple logistic regression were mixed type of seizures and more than 20 seizures before starting treatment (Table VI).

\section{Conclusion}

This study shows that there are a number of clinical factors that can be identified early in the course of childhood epilepsy that are predictive of poor seizure control. Knowledge of these factors will help us to discriminate our patients and pay more attention to those at risk of developing poorly controlled seizures.

\section{Conflict of Interest: None.}

\section{Acknowledgement}

Thanks and all praise to Almighty Allah, the beneficent, the merciful for providing us enough energy and patience to complete this article. Our special thanks and gratitude to Prof (Dr) Shahana Akhter Rahman, Pro vice Chancellor(Academic), Bangabandhu Sheikh Mujib Medical University, Dhaka, Bangladesh for providing instructions, encouragement and valuable advice from beginning of this study. We would like to express our sincere gratitude and gratefulness to all teachers, doctors and employee in the department of paediatrics, Bangabandhu Sheikh Mujib Medical University, Dhaka, Bangladesh for valuable suggestions and advices to complete this study.

\section{References}

1. Kalra V. Practical paediatric neurology. 2nd ed. New Delhi: Arya Publications;2008.

2. Holmes GL, Engel J Jr. Predicting medical intractability of epilepsy in children. How certain can we be? Neurology. 2001; 56:1430-1431.

https://doi.org/10.1212/WNL.56.11.1430

PMid:11402096 
3. Johnston MV. Seizures in childhood. In: Behrman RE, Kleigman RM and Jenson HB, editors. Nelson Text book of Paediatrics. 17th ed. Philadelphia: Saunders; 2004:1993-2009.

4. Chawla S, Aneja S, Kashyap R, Mallika V. Etiology and clinical predictors of intractable epilepsy .Pediatr Neurol. 2002; 27( 3): 186-191.

https://doi.org/10.1016/S0887-8994(02)00416-2

5. Devinsky O. Patients with refractory seizures. The new England journal of Medicine.1999; 340(20): 1565-1570.

https://doi.org/10.1056/NEJM199905203402008

PMid: 10332020

6. Camfield PR, Camfield CS, Gordon K, Dooley JM. If a first antiepileptic drug fails to control a childhood epilepsy what are the chances of success with the next drug? J Pediatr. 1997; 131: 821-824.

https://doi.org/10.1016/S0022-3476(97)70027-1

7. Annegers JP, Hausen WA, Elveback LR. Remission of Seizures and Relapse in patients with Epilepsy', Epilepsia. 1979; 20: 729-737.

https://doi.org/10.1111/j.1528-1157.1979.tb04857.x

\section{PMid:499118}

8. Holmes GL. Epilepsy in the developing brain: lessons from the la boratory and clinic. Epilepsia. 1997; 38: 12-30. https://doi.org/10.1111/j.1528-1157.1997.tb01074.x

PMid:9024181

9. Hiroyuki W, Hideo N, Masatoshi H, Takehiko M. Longterm medical, educational and social prognoses of childhood-onset epilepsy: a population-based study in a rural district of Japan. Brain and development. 2000; 22(4): 246-255.

10. Camfield C, Camfield P, Gordon K, Smith B, Dooley, JM. Outcome of childhood epilepsy: A polulation -based study with a simple predictive scoring system for those treated with medication. J Pediatr. 1993; 122: 861-868.

11. Berg AT, Levy SR, Novonty EJ, Shinnar S. Predictors of intractable epilepsy in childhood: a case-control study. Epilepsia.1996; 37(1): 24-30.

12. Gururaja A, Sztrihab L, Hertecantb J, Eapenc V. Clinical predictors of intractable childhood epilepsy. Journal of Psychosomatic Research. 2006; 61(3): 343-347.
13. Banu SH, Khan NZ, Jahan A, Parveen M, Rahman N, Boyd SH, et al. Profile of childhood epilepsy in Bangladesh. Developmental Medicine and Child Neurology. 2003; 45: 477-482.

https://doi.org/10.1017/S0012162203000884

https://doi.org/10.1111/j.1469-8749.2003.tb00943.x

\section{PMid:12828402}

14. Kwan P, Brodie MJ. Early identification of refractory epilepsy. N Eng J Med. 2000; 342: 314 - 319.

https://doi.org/10.1056/NEJM200002033420503

\section{PMid:10660394}

15. Malik MA, Hamid MH, Ahmed TM, Ali Q. Predictors of intractable childhood epilepsy. Journal of the College of Physicians and Surgeons Pakistan. 2008; 18(3):158-162.

16. Akhondian J, Heydarian F, Jafari, SA. Predictive factors of pediatric intractable seizure. Arch Iranian Med. 2006; 9(3): 236-239.

17. Singhvi JP, Sawhney IM, Lal V, Pathak A, Prabhakar, S. Profile of intractable epilepsy in a tertiary referral centre. Neurol India. 2000; 48(4): 351-356.

18. Oskoui M, Webster RI, Zhan X, Shevell, MI. Factors predictive of outcome in childhood epilepsy. Child Neurol. 2005; 20(11): 898-904.

19. Kwong KL, Sung WY, Wong SN, So KT. Early predictors of medical intractability in childhood epilepsy. Pediatr Neurol. 2003; 29( 1): 46-52.

20. Ko TS, Holmes GL. EEG and clinical predictors of medically intractable childhood epilepsy. Clinical Neurophysiology.1999; 110: 1245-1251.

https://doi.org/10.1016/S1388-2457(99)00068-1

21. Sillanpaa, M. Remission of seizures and predictors of intractability in long term follow up. Epilepsia. 1993; 34(5): 930-936.

22. Aicardi J. Diseases of the Nervous system in Childhood. 2ndedn. London: Mac Keith press;1998.

23. Ohtsuka Y, Yoshinaga H, Kobayashi K, Murakimi N, Yamatogi Y, Oka E, et al. Predictors and underlying causes of medically intractable localized related epilepsy in childhood. Pediatric neurology. 2001; 27:181- 191. 